\title{
Modelos murinos en el estudio del cáncer mamario
}

\author{
Murine models in the study of breast cancer \\ Juan Manuel Gutiérrez Meza,* Rosa Adriana Jarillo Luna*
}

\footnotetext{
* Sección de Estudios de Postgrado e Investigación. Escuela Superior de Medicina, Instituto Politécnico Nacional. CDMX, México.
}

Correspondencia:

Rosa Adriana Jarillo Luna E-mail: roadjalu12@gmail. com,rajarillo@ipn.mx

\section{RESUMEN}

El cáncer de mama en México ocupa la segunda causa de muerte en mujeres de 30 a 65 años, en 2019 se reportaron 35 casos nuevos/100,000 mujeres en este rango de edad. El término «cáncer de mama» no refleja una sola enfermedad, más bien debe considerarse como un repertorio de enfermedades relacionadas con características propias. En el estudio del cáncer mamario, los animales de experimentación han sido de indudable utilidad. El ratón es el más utilizado por varias razones, entre las que destacan el conocimiento de su genoma completo y ser el único animal que cuenta con sistemas eficientes de cultivo de células embrionarias pluripotenciales. Los modelos murinos se pueden clasificar en modelos inmunocomprometidos en los que se reproducen diferentes tipos de tumores mamarios mediante el implante de células de líneas cancerosas, o bien de fragmentos de tumores mamarios provenientes de pacientes. Los inmunocompetentes comprenden cepas que mediante la aplicación de carcinógenos desarrollan tumores, o que lo hacen de manera espontánea dadas las características de su genoma nativo, o bien por la manipulación de éste, existiendo varias cepas transgénicas o «knockout». En este trabajo se revisan las características generales de estos modelos murinos.

Palabras clave: Cáncer de mama, modelos murinos, CDX, PDX, GEMM.

\section{ABSTRACT}

The breast cancer in Mexico is the second cause of death in women aged 30 to 65, with 35 new cases / 100,000 women in this age range reported in 2019. The term «breast cancer» does not reflect a single disease; rather, it should be considered as a repertoire of diseases related to their own characteristics. In the study of breast cancer, experimental animals have been of undoubted utility. Mouse is the most widely used for several reasons, among which are the knowledge of its complete genome and being the only animal where there are efficient systems for cultivating pluripotent embryonic cells. Murine models can be classified into immunocompromised models, in which different types of mammary tumors are reproduced by implanting cancer cell lines or fragments of mammary tumors obtained of patients. The immunocompetent models, comprise strains that develop tumors through the application of carcinogens, or that do so spontaneously due to the characteristics of their native genome or by modifications thereof. Currently, there are several strains of transgenic or «knockout» mice. In this work the general characteristics of these murine models are reviewed.

Keywords: Breast cancer, murine models, $C D X, P D X, G E M M$.

Citar como: Gutiérrez MJM, Jarillo LRA. Modelos murinos en el estudio del cáncer mamario. Rev Mex Mastol. 2020; 10 (3): 83-92. https://dx.doi.org/10.35366/99157 


\section{INTRODUCCIÓN}

El cáncer de mama $(\mathrm{CM})$ es el segundo tipo de cáncer más común del mundo, el término «cáncer de mama» no refleja una sola enfermedad, más bien debe considerarse como un repertorio de enfermedades relacionadas que se pueden clasificar en distintos subtipos, cada uno con características fenotípicas, moleculares o genéticas accionables, además con distinto pronóstico. En México, el CM es a partir del año 2006 la segunda causa de muerte en mujeres de 30 a 54 años. En 2018 se registraron 7,257 defunciones en mujeres por CM y en 2019 por cada 100,000 mujeres de 20 años o más se reportaron 35.24 casos nuevos. Siendo la tasa de mortalidad nacional de 17.19 defunciones por cada 100,000 mujeres mayores de 20 años. ${ }^{1}$ En promedio, las mujeres mexicanas desarrollan cáncer de mama una década antes que las europeas o estadounidenses (51 contra 63 años).

Los tumores de mama parecen experimentar un patrón reproducible de progresión desde una neoplasia in situ hasta una enfermedad localmente invasiva y posteriormente metastásica. Muchos de estos tumores también siguen una progresión análoga desde la dependencia hormonal, pasando por la independencia hormonal, hasta la resistencia a los antiestrógenos; igualmente cursan desde la susceptibilidad a fármacos hasta la resistencia a éstos. Estos patrones de comportamiento biológico son fundamentales para la patogenia del cáncer de mama; hay muchos efectores fisiológicos que probablemente influyan en el crecimiento y la progresión del CM, y son tan diversos como endocrinológicos, inmunológicos y conductuales; es en estas áreas donde el uso de animales de laboratorio es fundamental para lograr la completa comprensión de esta entidad. ${ }^{2}$ El objetivo del presente trabajo es hacer una breve revisión de los distintos modelos animales utilizados en el estudio del CM.

MODELOS ANIMALES EN EL ESTUDIO DE CÁNCER DE MAMA

Dentro de los modelos experimentales para el estudio del CM están los roedores de laboratorio como la rata y el ratón, éste último modelo animal ofrece muchas ventajas como son:
- Gran parte de sus procesos bioquímicos son similares al humano.

- Tienen un tiempo generacional muy corto, son muy prolíficos y se adaptan fácilmente a la vida en los bioterios, lo que permite controlar las variables ambientales en los experimentos.

- Comparte con el hombre el privilegio de pertenecer a las especies de mamíferos mejor estudiadas desde el punto de vista genético. El trabajo acumulado durante un siglo de investigaciones ha resultado en una inmensa cantidad de documentación sobre los fenotipos mutantes, las características de las líneas, los mapas genéticos y la secuencia completa del genoma.

- Existe una gran cantidad de líneas genéticamente definidas como las consanguíneas y congénicas, además de cientos de mutaciones y un gran número de rearreglos cromosómicos disponibles.

- Es el único animal que cuenta con sistemas eficientes de cultivo de células embrionarias pluripotenciales, lo que permite la realización de mutaciones dirigidas (ratones $\mathrm{KO}$ constitutivos y condicionales).

Por lo que existe un gran número de modelos murinos utilizados en el estudio del cáncer mamario.

\section{MODELOS DE RATONES INMUNOCOMPETENTES}

Estos animales desarrollarán neoplasias mamarias de forma espontánea o por la inducción con carcinógenos. Los tumores en estos animales tienen un largo periodo de latencia, por lo que una vez que el tumor se ha establecido, se pueden injertar células o tejidos derivados del tumor en animales con las mismas características genéticas, estableciendo modelos singénicos que mantienen las mismas características del tumor primario y tasas de crecimiento rápido; sin embargo, no permiten estudiar el proceso de iniciación del tumor.

En general los tumores en ratones tratados con carcinógenos a menudo expresan una variedad de alteraciones genómicas, incluidas mutaciones en PTEN, aumento de la expresión de CCND1 y MYC, y activación de importan- 


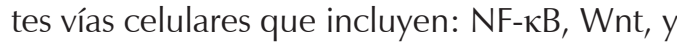
$\mathrm{PI} 3 \mathrm{~K} / \mathrm{AKT}^{3,4}$

Como ejemplos de los agentes cancerígenos tenemos a la $\mathrm{N}$-metil-N-nitrosourea (MNU), éste es un agente alquilante, y exhibe su toxicidad mediante la transferencia de sus grupos metilo a las núcleo-bases. Su efecto oncogénico parece deberse a la acción metilante de estos compuestos en la guanina, lo que daría lugar a la aparición de cambios irreversibles en el ADN. ${ }^{5}$ Este modelo permite examinar el proceso de carcinogénesis en el momento de iniciación del mismo y su evolución hacia carcinoma. ${ }^{6,7}$

La cepa de ratón en la que se induce el carcinoma por este agente es la C57BL/6J Apc$\mathrm{min} /+$ reportada en Mouse Genome Informatics.

El 7,12-dimetilbenzo (a) antraceno (DMBA) es un hidrocarburo aromático policíclico con la capacidad de desarrollar adenocarcinomas mamarios bien diferenciados en ratones y ratas, estos tumores son sensibles a las hormonas y morfológicamente similares a los carcinomas de mama humanos del tipo adenomioepitelial y mioepitelial. ${ }^{8,9}$

El acetato medroxiprogesterona (MPA) induce en ratones BALB/C carcinomas mamarios ductales metastásicos que retienen sus receptores para prolactina, estrógeno y progesterona, por lo que responden a hormonas. ${ }^{10}$

En cuanto a los modelos espontáneos, algunos involucran ratones que desarrollan tumores de origen natural (no genéticamente modificados). En estos modelos de animales inmunocompetentes se pueden estudiar nuevas terapias inmunológicas. Por ejemplo, con anti-PD-1/PD-L1, (PD-1, receptor de muerte programada o CD279). Debido a las características invasivas de estos tumores murinos, ${ }^{11}$ también son útiles para estudiar los efectos antitumorales y antimetastásicos de nuevos fármacos.

\section{MODELOS DE RATONES INMUNOCOMPROMETIDOS. XENOINJERTOS}

Estos modelos consisten en el trasplante de líneas celulares cancerosas (CDX) o de células derivadas o fragmentos de tumores humanos (PDX) en animales inmunocomprometidos, esto con el objeto de evitar la respuesta inmunitaria de rechazo del animal.

Los animales que se usan más comúnmente en PDX son ratones diabéticos no obesos.

(NOD)-SCID, NOD.Cg-Prkdc $c^{\text {scid }} \| 2 \mathrm{rg}^{\text {tm } 1 \text { Wjl }} /$ SzJ. (NSG) o NOD.Cg-Prkdcscid II2rgtm1 Sug/ Shijic (NOG). Estos animales presentan alta inmunodeficiencia debido a la baja actividad de células NK. Los ratones desnudos (nude) o con inmunodeficiencia combinada (SCID) también son utilizados en modelos de CDX. ${ }^{12}$

La desventaja de utilizar animales inmunocomprometidos es que la pérdida de la función inmunitaria no permite estudiar los efectos protumorigénicos o antitumorigénicos ejercidos por el sistema inmunitario. Sin embargo, el reciente desarrollo de ratones humanizados obtenidos injertando células troncales hematopoyéticas humanas que se diferencian en células inmunocompetentes ha contribuido a resolver este problema. ${ }^{13}$

\section{XENOINJERTOS DE CÉLULAS CANCEROSAS (CDX)}

El uso de líneas celulares cancerosas tiene ventajas, por ejemplo, son de fácil manejo, tienen un número infinito de replicaciones y alto grado de homogeneidad; sin embargo, tienen desventajas, las células frecuentemente presentan cambios genotípicos y fenotípicos a lo largo del tiempo de cultivo, lo que puede dar lugar a la selección de clonas con mayor tasa de crecimiento, esto ya ha sido reportado por otros autores. ${ }^{14,15}$ Otra desventaja es que un buen número de estas células han sido obtenidas de fluidos de pacientes con metástasis, por lo que no son células del tumor original y son clonas agresivas, por lo que al ser trasplantadas al animal no reflejan exactamente la evolución natural de la neoplasia, produciendo tumores de rápido crecimiento. Las vías por las cuales las células se pueden injertar en el animal son por vía sanguínea, a través de la vena de la cola, aplicados de forma subcutánea en los flancos del animal o bien de forma ortotópica en el panículo adiposo de la glándula mamaria inguinal. Esto último tiene ventajas, ya que las células tumorales se desarrollan en un ambiente celular más real con la participación del estroma.

A pesar de los inconvenientes del uso de CDX, éstos han aportado mucha información 
del CM, por ejemplo, el proceso de metástasis, las características genéticas y el ensayo de nuevos anticancerígenos y otras terapéuticas. Las características de algunas líneas celulares usadas en CDX se muestran en la Tabla 1. ${ }^{16-20}$ Y en la Figura 1 se describe la relación entre las características del tumor con las características de las líneas celulares utilizadas en CDX. ${ }^{20}$

\section{XENOINJERTO DERIVADO DE PACIENTE (PDX)}

En los modelos PDX, tumores primarios o fragmento de ellos son trasplantados subcutánea u ortotópicamente en ratones inmunodeprimidos (nude, NOD/SCID o NSG). Estos modelos son adecuados para estudios en busca de biomarcadores de respuesta o resistencia a fármacos así como del potencial anticanceroso de nuevos fármacos terapéuticos

Al contrario de las líneas cancerosas ya establecidas, los PDX se propagan a través de generaciones sucesivas en animales vivos y al igual que las líneas celulares son una fuente renovable de tejido canceroso, presentan características semejantes al tumor original como el patrón histológico, expresan los mismos genes, tienen patrones estables en la expresión de proteínas, además de que la heterogeneidad del tumor original se preserva y su respuesta a la terapia farmacológica es altamente predictiva. ${ }^{21}$

En la Figura 2 se muestra de manera esquemática el establecimiento de los modelos de PDX. ${ }^{22}$

La implantación del tumor de manera ortotópica en la grasa mamaria es óptima, ya que recapitula el microambiente estromal del tumor, que comprende la vasculatura (la cual es mayor que en los tumores subcutáneos), adipocitos, fibroblastos y macrófagos asociados al tumor, todas estas células secretan factores de crecimiento y citocinas que impactan en el desarrollo del tumor.

Dada la importancia del estroma se han realizado trabajos para humanizar el lecho adiposo de la glándula mamaria murina, implantando líneas celulares de fibroblasto o células mesenquimales, estas últimas contribuyen a mantener el fenotipo del tumor y su irrigación. Un aspecto importante es que independientemente de la positividad a receptores estrogénicos, la suplementación con estrógenos contribuye al crecimiento del tumor.

El objetivo final de establecer estos modelos es poder ofrecer una terapia personalizada a las pacientes, en lugar de someterlas a esquemas de tratamiento estereotipados; sin embargo, el uso de estos modelos todavía es algo limitado debido al tiempo típico requerido para que el tumor se establezca en el huésped. No obstante, los PDX están cobrando popularidad por reportes exitosos en cuanto a la terapia personalizada, por ejemplo, Garralda E y colaboradores en 2014 reportaron que 14 pacientes con tumores sólidos avanzados fueron tratadas con drogas seleccionadas de acuerdo a los resultados obtenidos de los PDX, 11 de estas pacientes presentaron una remisión parcial durable. ${ }^{23}$ En la Figura 3 se muestra el esquema de un modelo PDX ideal de terapia personalizada. Para ello es necesario establecer el perfil genético del tumor original y verificar que ese patrón coincida con los tumores generados en los animales, las drogas son probadas en los

\begin{tabular}{|c|c|c|c|c|}
\hline \multicolumn{5}{|c|}{$\begin{array}{c}\text { Tabla 1: Características de algunas líneas celulares } \\
\text { utilizadas en líneas celulares cancerosas. }{ }^{16-20}\end{array}$} \\
\hline Línea celular & Origen & Tipo de injerto & Patología & Metástasis \\
\hline MCF-7 & Líquido pleural & Ortotópico & Carcinoma ductal invasivo (tipo A) & Sí \\
\hline T47-D & Líquido pleural & Ortotópico & Carcinoma ductal invasivo (tipo A) & Sí \\
\hline MDA-MB-231 & Líquido pleural & Subcutáneo & Adenocarcinoma (basal B) & Sí \\
\hline MDA-MB-435 & Líquido pleural & Ortotópico & Carcinoma ductal invasivo (basal B) & Sí \\
\hline SUM1315M02 & Piel & Ortotópico & Carcinoma ductal invasivo (basal B) & Sí \\
\hline BT474 & Mama & Subcutáneo & Carcinoma ductal invasivo (tipo B) & Sí \\
\hline
\end{tabular}




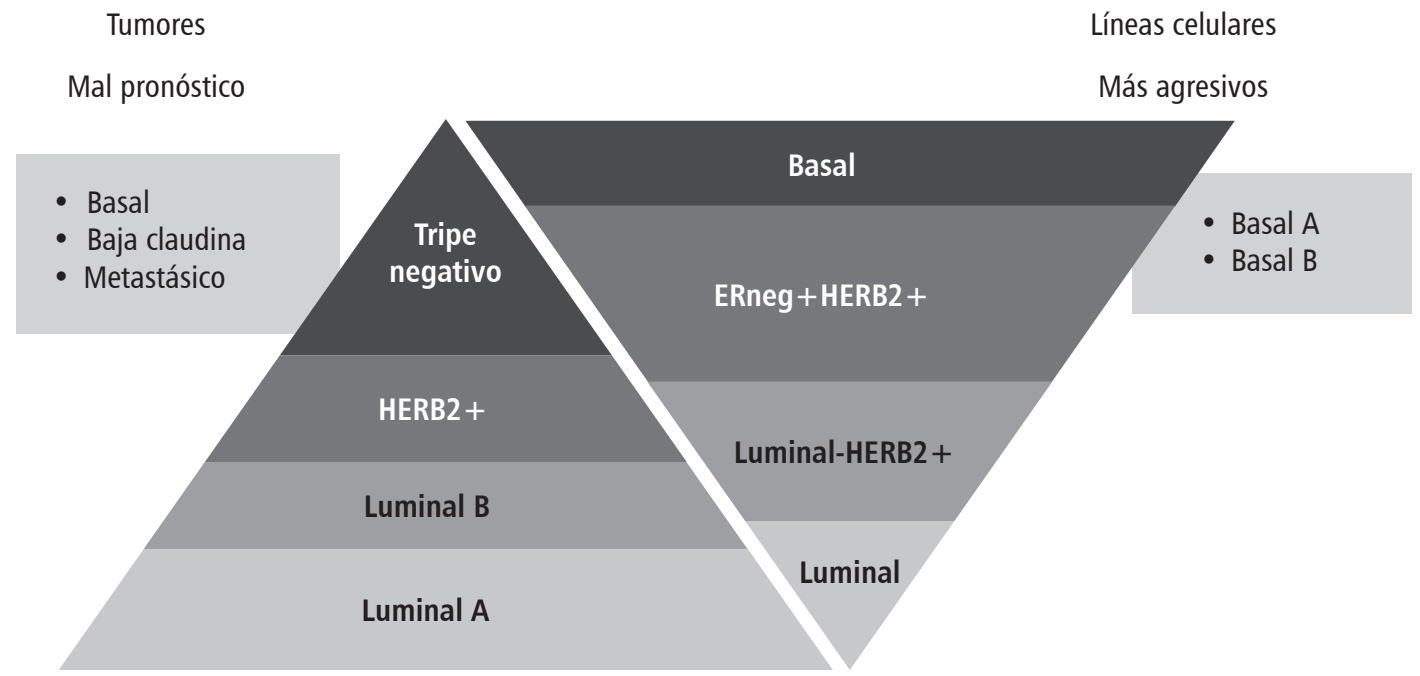

Mejor pronóstico

Menos agresivos

Figura 1: Comparación de las líneas celulares con los subtipos de tumores. Las características morfológicas de los subtipos en tumores y líneas celulares concuerdan bien con tumores luminales, que tienen mejor pronóstico y líneas celulares luminales menos agresivas que en los tumores y líneas celulares triple negativas. ${ }^{20}$

animales, determinando el mejor tratamiento para la paciente. ${ }^{22}$

\section{MODELOS MURINOS DISEÑADOS GENÉTICAMENTE PARA EL ESTUDIO DE CÁNCER DE MAMA (GEMM)}

La patogénesis del CM involucra múltiples eventos genéticos, la mayoría de los cambios genéticos en el CM humano caen en las categorías de ganancia o mutaciones de protooncogenes, genes de reparación del ADN y la pérdida o mutación de los genes supresores de tumores.

La mayoría de la ganancia en la función génica en el CM humano involucra a los genes c-myc, y erB-2 o a la banda 11q13; la pérdida de la función involucra a los genes p53, a la familia de los genes BRCA, pérdida de heterogeneidad de genes supresores de tumores, o en la región de la fosfatidilinositol-3,4,5-trisfosfato 3-fosfatasa (PTEN), esta última observada en tumores particularmente agresivos. ${ }^{24}$

En la actualidad existe un gran número de modelos animales para estudiar estas mutaciones en el cáncer de mama: ${ }^{24,25}$ los animales transgénicos en los que se induce la expresión en niveles altos de genes específicos, los ratones genoprivos o «knockout» (KO) en los que existe ablación de genes específicos, los «knockin» en los que se ha sustituido una secuencia génica por otra diferente o modificada. La combinación de modelos «knockout» con modelos transgénicos en los que la expresión de la recombinasa Cre está vinculada al transgén, también ha permitido el estudio de facetas específicas del desarrollo tumoral.

\section{MODELOS TRANSGÉNICOS DE CÁNCER DE MAMA}

Los ratones transgénicos son producidos a través de la microinyección pronuclear de un gen de interés (transgén), por ejemplo, un oncogén bajo el control de varios promotores específicos de la glándula mamaria. Los embriones se colocan en el oviducto de un ratón hembra preñada mediante microcirugía y la progenie posterior se analiza para detectar la presencia del transgén por medio de un análisis de Southern Blot. La mayor complicación de esta técnica de generación de animales transgénicos es no poder determinar el sitio de inserción ni el número de copias del transgén, ya que se producen al azar. ${ }^{26}$

Otro método de introducir el transgén es la recombinación homóloga, esta técnica emplea regiones de homología entre el ADN endógeno (cromosómico) y el exógeno (trans- 
gén) para insertar el gen de interés en un área específica del cromosoma. Esta técnica permite predecir el sitio donde terminará insertado el gen exógeno y evita el inconveniente de la inserción al azar como sucede en la inyección de pronúcleos, además de que se utilizan las regiones reguladoras endógenas. Sin embargo, la recombinación génica no permite su empleo directo en embriones, por lo cual debe realizarse en células pluripotenciales: las células madre embrionarias obtenidas de embriones en etapa de blastocisto, una vez seleccionadas las células que incorporaron correctamente el gen de interés, se inyectan en un embrión huésped. Los animales que se obtienen presentan dos tipos de tejido, el propio del huésped y el transgénico proveniente de las células madre embrionarias. Estos animales producirán una progenie con el genotipo normal del huésped y con el genotipo transgénico, pudiéndose generar líneas estables con la modificación genética específica. ${ }^{27}$

Dentro de los promotores selectivos de la glándula mamaria que se emplean para la expresión de los transgenes en los modelos de ratones transgénicos están: 1) el virus del tumor mamario del ratón (MMTV) de repetición terminal larga (LTR), 2) el promotor del gen de la proteína ácida del suero de leche (WAP). El MMTV-LTR es activo a través del desarrollo mamario y su actividad transcripcional se incrementa durante la gestación, el promotor de WAP está activo sólo hasta la mitad de la gestación (Tabla 2). Otros promotores menos usados son los de la beta-lactoalbúmina y la metalotioneina.

1. El (MMTV LTR es un retrovirus altamente infeccioso en varias cepas de ratones como las cepas BR6, C3H, GR, RIII, e inducen tumores por mutagénesis insercional en el ADN del genoma del ratón, desregulando la expresión de genes adyacentes. El MMTV LTR posee elementos de respuesta para glucocorticoides, andrógenos y progesterona que son regulados durante el ciclo estral en las glándulas mamarias vírgenes. La expresión de genes adyacentes a la LTR está regulada durante el embarazo y alcanza su punto máximo durante la lactancia. ${ }^{28}$

Bajo el control de este promotor se puede controlar la expresión de varios oncogenes como el oncogén ErbB2 que funciona como marcador de pronóstico, especialmente en tumores de pacientes con metástasis en los ganglios linfáticos. Los ratones transgénicos que expresan el oncogén ErbB2 impulsado por el promotor MMTV LTR, desarrollan adenocarcinomas multifocales a las 30 semanas de edad. Estos adenocarcinomas hacen metástasis a los pulmones. ${ }^{29-32}$

En los ratones transgénicos, la expresión de la oncoproteína T media de polioma

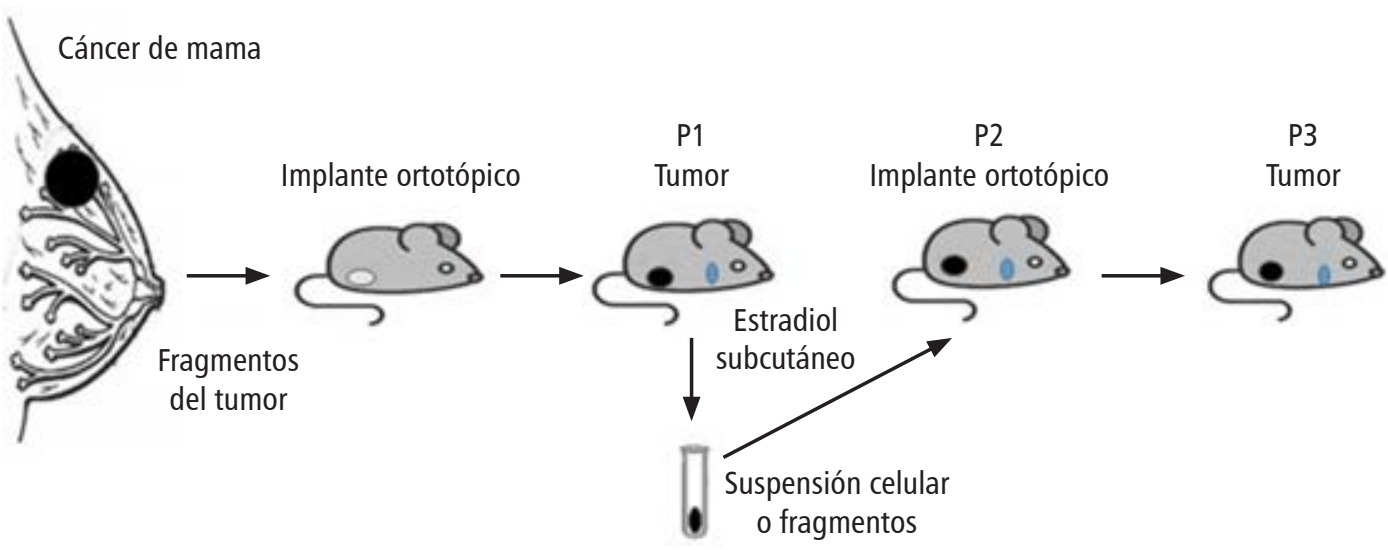

Figura 2: Modelo de PDX en ratón. Fragmentos del tumor del paciente son implantados en la grasa de la glándula mamaria inguinal junto con un implante subcutáneo de estrógenos. Cuando el tumor se ha establecido se toman fragmentos, los cuales se pueden conservar en congelación para ser utilizados como stock. Éstos de implantan nuevamente de la misma forma para reproducir nuevamente el tumor. Para establecer el tumor se necesitan por lo menos tres pases en los animales. ${ }^{22}$ 


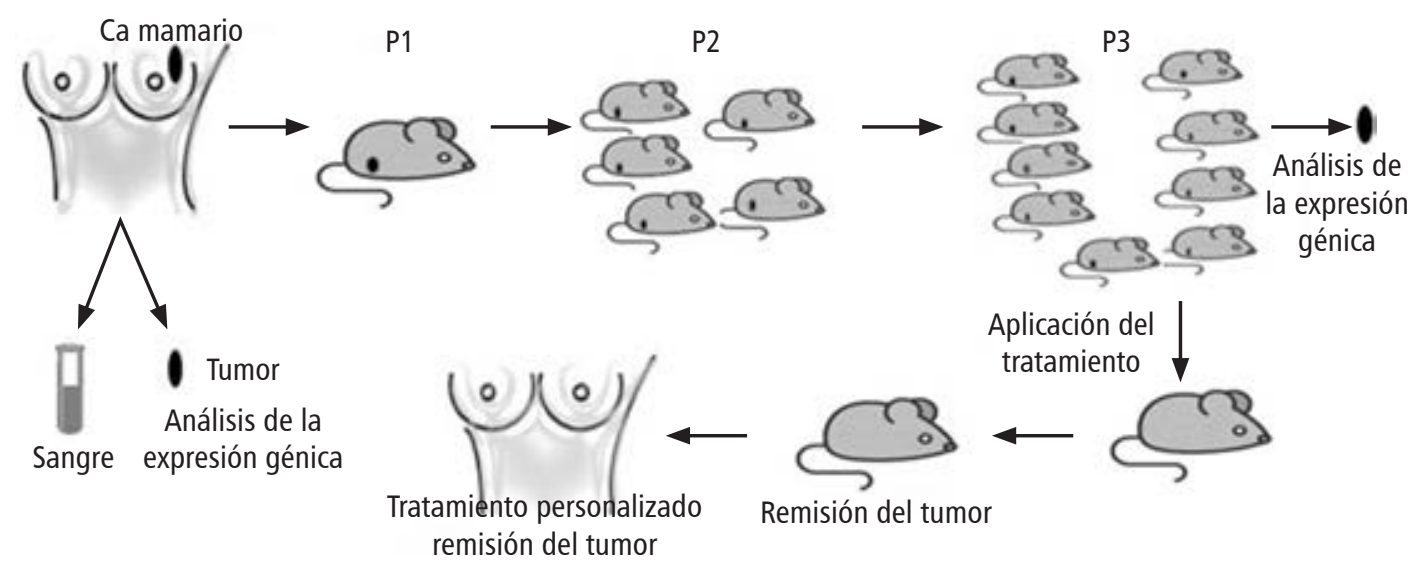

Figura 3: Modelo ideal de terapia personalizada basada en modelos PDX. De los fragmentos extraídos del tumor de la paciente se establece el perfil genético del tumor original para verificar que ese patrón coincida con los tumores generados en los animales, después los tratamientos son probados en los animales, se determina el mejor para la paciente logrando la remisión del cáncer. ${ }^{22}$

transgénico (PyMT), bajo el control del promotor MMTV, induce el desarrollo de adenocarcinomas multifocales y metástasis a pulmones y ganglios linfáticos. Estos ratones transgénicos desarrollan tumores palpables entre cuatro y ocho semanas de edad. De estos ratones, $90 \%$ muestra metástasis pulmonar a las 14 semanas de edad. ${ }^{31}$

La ciclina D1 participa en el desarrollo de tumores alveolares de glándulas. En ratones transgénicos MMTV-Cyclin D1 se desarroIlan tumores ER-positivo dependiente de estrógenos que se desarrollan a partir de los 22 meses de edad. ${ }^{33,34}$

El protooncogén Wnt-1 se identificó por primera vez en tumores mamarios de ratón. Este oncogén está ausente en la glándula mamaria y no se ha implicado directamente en el cáncer de mama humano. Sin embargo, otros miembros de la familia Wnt se expresan en la mama y se sobreexpresan en el cáncer de mama, ${ }^{35}$ donde se relacionan con la sobreexpresión de $\beta$-cateninan, lo que se correlaciona con un mal pronóstico en pacientes con cáncer de mama. De los ratones transgénicos MMTV-Wnt1, 50\% desarrollan adenocarcinoma mamario a las 32 semanas de edad y metástasis a los ganglios linfáticos y los pulmones.

El protooncogén c-Myc funciona como un factor de transcripción que activa la expresión de varios genes necesarios para la progresión del ciclo celular de la fase G1 a la S. c-Myc se sobreexpresa en $45-70 \%$ de los tipos de cáncer de mama humanos y su amplificación se correlaciona con un mal pronóstico del paciente. ${ }^{36}$ Los ratones transgénicos MMTV-c-Myc desarrollan una sobreexpresión de c-Cyc en las glándulas mamarias. ${ }^{37}$ Estos ratones desarrollan adenocarcinomas mamarios en hembras multíparas con una incidencia de $100 \%$.

2. El promotor del gen WAP es regulado de manera hormonal por prolactina, hidrocortisona, estrógeno e insulina, y activa fuertemente la expresión de genes específicos mamarios durante la mitad del embarazo y lactancia. ${ }^{38}$ El oncogén Ras contribuye al cáncer humano. El desarrollo y la expresión del oncogén $\mathrm{H}$-ras impulsado por el promotor WAP provoca inestabilidad genómica, adenocarcinoma y metástasis pulmonar en ratones. ${ }^{39,40}$ En los ratones transgénicos los tumores de las glándulas mamarias se desarrollan a las 24 semanas de edad.

3. El promotor C3 (1) dirige la expresión transgénica al epitelio tanto de la mama como de las glándulas prostáticas. ${ }^{41} \mathrm{~A}$ diferencia de los promotores descritos anteriormente, la expresión de este promotor no se ve influenciado por el embarazo y, por lo tanto, algunos de los efectos artificiales del embarazo en modelos transgénicos impul- 
sados por MMTV y WAP puede evitarse con este promotor. ${ }^{41,42}$ En ratones transgénicos que expresan en transgén del antígeno $\mathrm{T}$ grande (Tag) del virus vacuolante del simio (SV40) bajo el control del promotor C3 (1) conduce al desarrollo de adenocarcinomas de glándula mamaria en ratones hembra ${ }^{43} \mathrm{a}$ las 21 semanas de edad, lo que se observa en $90 \%$ de los ratones.

\section{MODELOS «KNOCKOUT» DE CÁNCER DE MAMA}

Los ratones «knockout» en los que se inactiva un gen de interés, son producidos mediante la introducción de un vector que codifica una versión modificada y no funcional del gen en células madre de embrión de ratón. Los modelos «knockout» son adecuados para investigar el papel de los genes supresores de tumores en tipos de cáncer de mama.

Los genes supresores de tumores desempeñan un papel crucial en la regulación y limitación del crecimiento y la proliferación celular. En la actualidad se han descrito varios genes supresores de tumores que participan en diversos procesos como son: la regulación de la progresión del ciclo celular, la inhibición de la señalización del receptor del factor de crecimiento, la promoción de la apoptosis y la regulación de los mecanismos de reparación del ADN. En general, la pérdida o inactivación de ambos alelos de un gen supresor de tumores promueve el desarrollo de tumores.

\section{- Modelos «knockout» de BRCA1}

BRCA1 (Breast cancer 1) es una fosfoproteína nuclear involucrada en el mantenimiento de la estabilidad genómica que actúa como supresor de tumores. Las mutaciones de BRCA1 están presentes en $50 \%$ de las pacientes con cáncer de mama hereditario y en aproximadamente 90\% de las pacientes con cáncer de mama y ovario hereditario. Los ratones «knockout» para BRCA1 han ido generando el sistema Cre-loxP, que permite llevar a cabo deleciones, inserciones, translocaciones e inversiones en sitios específicos del ADN. En estos animales se ha observado un aumento en la apoptosis y un desarrollo ductal anormal en las células epiteliales mamarias. Los tumores presentan inestabilidad genómica como aneuploidías similares a las observadas en el cáncer de mama humano. ${ }^{28}$

- Modelos p53 transgénicos y «knockout»

El gen supresor de tumores p53 se encuentra mutado en aproximadamente $25 \%$ de los tumores de mama. ${ }^{44,45}$ Los ratones p53-R172H poseen una sustitución de arginina a histidina en el residuo de aminoácido 172 en el gen p53, el cual se expresa bajo el control transcripcional del promotor WAP. ${ }^{46}$ Esta mutación es equivalente a una de las mutaciones en el gen p53 humano. El transgén no afecta el desarrollo normal de la glándula mamaria de ratones; sin embargo, los ratones fueron más susceptibles al desarrollo de tumores mamarios tras la administración del carcinógeno químico dimetilbenz(a)antraceno en comparación con los animales silvestres.

- Modelos «knockout» condicionales

En los párrafos anteriores hemos mencionado animales que son transgénicos o «knockout» desde su nacimiento, pero además se cuenta con animales en los que se puede «desactivar» el gen que hasta el momento se habían

\begin{tabular}{llll} 
& \multicolumn{2}{c}{ Tabla 2: Promotores específicos de la glándula mamaria. } \\
Promotor & Origen & Expresión & Activación \\
\hline MMTV-LTR & Virus tumoral de glándula mamaria de ratón & Células epiteliales de glándula mamaria & Hormonas esteroideas \\
WAP & Proteína ácida del suero & Epitelio secretor de la glándula de mama & Hormonas lactogénicas \\
C3(1) & $\begin{array}{l}\text { Proteína de unión a esteroides } \\
\text { de próstata de rata }\end{array}$ & $\begin{array}{l}\text { Células epiteliales de la próstata } \\
\text { y glándula mamaria }\end{array}$ & $\begin{array}{l}\text { Estrógenos (ductal y alveolar de } \\
\text { epitelio mamario) }\end{array}$ \\
\hline
\end{tabular}


desarrollado normalmente, y esto se puede llevar a cabo haciendo uso del sistema Cre/ loxP. Cre es una enzima recombinasa que actúa en sitios flanqueados por loxP, si ambos sitios loxP se encuentran en la misma dirección, la enzima cataliza la escisión del ADN que se ubica entre ellos. En el animal transgénico se pueden colocar dos sitios loxP flanqueando al gen que se quiere anular y si el promotor que se emplea para controlar la expresión de Cre se activa en un momento concreto, tendremos un «knockout» controlado temporalmente. De forma similar, si el promotor es sensible a la presencia de fármacos tendremos un «knockout» inducible.

El uso de estos animales «knockout» condicionales permitió apoyar la teoría de que la deficiencia de BRCA1 no causa directamente la formación de tumores, sino que desencadena la inestabilidad genética, que con el tiempo resulta en tumorigénesis después de adquirir progresivamente otras alteraciones permisivas, incluida la inactivación de p53 y la activación de oncogenes. ${ }^{47}$ Otro ejemplo de la utilidad de estos modelos fue determinar el papel de Pten y ErbB2 en el incremento de la angiogénesis en tumores mamarios multifocales y metastásicos. ${ }^{48}$

Diversos modelos «knockout» condicionales son revisados por Deng CX. ${ }^{49}$

\section{CONCLUSIÓN}

El cáncer de mama es el tipo de cáncer más común en mujeres. La combinación de técnicas avanzadas ha posibilitado el desarrollo de modelos animales, los cuales replican muchas características esenciales de la variedad de enfermedad que se encuentra en cáncer de mama humano, lo que ha permitido una comprensión más profunda de los aspectos fundamentales que median la iniciación, el desarrollo y la progresión de la enfermedad a través del estudio de los mecanismos moleculares subyacentes a la progresión del cáncer de mama y la metástasis.

\section{BIBLIOGRAFÍA}

1. Hanahan D, Weinberg RA. Hallmarks of cancer: the next generation. Cell. 2011; 144 (5): 646-674.
2. Clarke R. Animal models of breast cancer: their diversity and role in biomedical research. Breast Cancer Res Treat. 1996; 39 (1): 1-6.

3. Currier N, Solomon SE, Demicco EG, Chang DL, Farago $M$, Ying $H$ et al. Oncogenic signaling pathways activated in DMBA-induced mouse mammary tumors. Toxicol Pathol. 2005; 33 (6): 726-737.

4. Abba MC, Zhong Y, Lee J, Kil H, Lu Y, Takata Y et al. DMBA induced mouse mammary tumors display high incidence of activating Pik3caH1047 and loss of function Pten mutations. Oncotarget. 2016; 7 (39): 64289-64299.

5. Lu J, Jiang C, Mitrenga T, Cutter G, Thompson HJ. Pathogenic characterization of 1-methyl-1-nitrosoureainduced mammary carcinomas in the rat. Carcinogenesis. 1998; 19 (1): 223.

6. Thompson HJ, Adlakha H. Dose-responsive induction of mammary gland carcinomas by the intraperitoneal injection of 1-methyl-1-nitrosourea. Cancer Res. 1991; 51 (13): 3411-3415.

7. Tsubura A, Lai YC, Miki H, Sasaki T, Uehara N, Yuri T et al. Review: Animal models of N-Methyl-N-nitrosoureainduced mammary cancer and retinal degeneration with special emphasis on therapeutic trials. In Vivo. 2011; 25 (1): 11-22.

8. Rehm S. Chemically induced mammary gland adenomyoepitheliomas and myoepithelial carcinomas of mice. Immunohistochemical and ultrastructural features. Am J Pathol. 1990; 136 (3): 575-384.

9. Kerdelhue B, Forest C, Coumoul X. Dimethyl-Benz(a) anthracene: A mammary carcinogen and a neuroendocrine disruptor. Biochim Open. 2016; 3: 49-55.

10. Lanari C, Lamb CA, Fabris VT, Helguero LA, Soldati R, Bottino MC et al. The MPA mouse breast cancer model: evidence for a role of progesterone receptors in breast cancer. Endocr Relat Cancer. 2009; 16 (2): 333-350.

11. Rashid OM, Takabe K. Animal models for exploring the pharmacokinetics of breast cancer therapies. Expert Opin Drug Metab Toxicol. 2015; 11 (2): 221-230.

12. Murayama T, Gotoh N. Patient-derived xenograft models of breast cancer and their application. Cells. 2019; 8 (6): 621.

13. Walsh NC, Kenney LL, Jangalwe S, Aryee KE, Greiner $\mathrm{DL}$, Brehm MA et al. Humanized mouse models of clinical disease. Annu Rev Pathol. 2017; 12: 187-215.

14. Osborne CK, Hobbs K, Trent JM. Biological differences among MCF-7 human breast cancer cell lines from different laboratories. Breast Cancer Res Treat. 1987; 9 (2): 111-121.

15. Bahia H, Ashman JN, Cawkwell L, Lind M, Monson JR, Drew PJ et al. Karyotypic variation between independently cultured strains of the cell line MCF-7 identified by multicolour fluorescence in situ hybridization. Int J Oncol. 2002; 20 (3): 489-494.

16. Burdall SE, Hanby AM, Lansdown MR, Speirs V. Breast cancer cell lines: friend or foe? Breast Cancer Res. 2003; 5 (2): 89-95.

17. Ding H, Quan H, Yan W, Han J. Silencing of SOX12 by shRNA suppresses migration, invasion and proliferation of breast cancer cells. Biosci Rep. 2016; 36 (5): e00389.

18. Chavez KJ, Garimella SV, Lipkowitz S. Triple negative breast cancer cell lines: one tool in the search for better 
treatment of triple negative breast cancer. Breast Dis 2010; 32 (1-2): 35-48.

19. Liang Y, Benakanakere I, Besch-Williford C, Hyder RS, Ellersieck MR, Hyder SM. Synthetic progestins induce growth and metastasis of BT-474 human breast cancer xenografts in nude mice. Menopause. 2010; 17 (5): 1040-1047.

20. Dai X, Cheng H, Bai Z, Li J. Breast cancer cell line classification and its relevance with breast tumor subtyping. J Cancer. 2017; 8 (16): 3131-3141.

21. Dobrolecki LE, Airhart SD, Alferez DG, Aparicio S, Behbod F, Bentires-Alj M et al. Patient-derived xenograft (PDX) models in basic and translational breast cancer research. Cancer Metastasis Rev. 2016; 35 (4): 547573.

22. Whittle JR, Lewis MT, Lindeman GJ, Visvader JE. Patient-derived xenograft models of breast cancer and their predictive power. Breast Cancer Res. 2015; 17: 17.

23. Garralda E, Paz K, Lopez-Casas PP, Jones S, Katz A, Kann LM et al. Integrated next-generation sequencing and avatar mouse models for personalized cancer treatment. Clin Cancer Res. 2014; 20 (9): 2476-2484.

24. Hutchinson JN, Muller WJ. Transgenic mouse models of human breast cancer. Oncogene. 2000; 19 (53): 6130-6137.

25. Hanahan D, Wagner EF, Palmiter RD. The origins of oncomice: a history of the first transgenic mice genetically engineered to develop cancer. Genes Dev. 2007; 21 (18): 2258-2270.

26. Gama Sosa MA, De Gasperi R, Elder GA. Animal transgenesis: an overview. Brain Struct Funct. 2010; 214 (2-3): 91-109.

27. Borowsky AD. Choosing a mouse model: experimental biology in context--the utility and limitations of mouse models of breast cancer. Cold Spring Harb Perspect Biol. 2011; 3 (9): a009670.

28. Menezes ME, Das SK, Emdad L, Windle JJ, Wang XY, Sarkar D et al. Genetically engineered mice as experimental tools to dissect the critical events in breast cancer. Adv Cancer Res. 2014; 121: 331-382.

29. Park JW, Neve RM, Szollosi J, Benz CC. Unraveling the biologic and clinical complexities of HER2. Clin Breast Cancer. 2008; 8 (5): 392-401.

30. Allred DC, Clark GM, Molina R, Tandon AK, Schnitt SJ, Gilchrist KW et al. Overexpression of HER-2/neu and its relationship with other prognostic factors change during the progression of in situ to invasive breast cancer. Hum Pathol. 1992; 23 (9): 974-979.

31. Guy CT, Cardiff RD, Muller WJ. Induction of mammary tumors by expression of polyomavirus middle T oncogene: a transgenic mouse model for metastatic disease. Mol Cell Biol. 1992; 12 (3): 954-961.

32. Guy CT, Cardiff RD, Muller WJ. Activated neu induces rapid tumor progression. J Biol Chem. 1996; 271 (13): 7673-7678.

33. Hwang TS, Han HS, Hong YC, Lee HJ, Paik NS. Prognostic value of combined analysis of cyclin D1 and estrogen receptor status in breast cancer patients. Pathol Int. 2003; 53 (2): 74-80.

34. Sutherland RL, Musgrove EA. Cyclins and breast cancer. J Mammary Gland Biol Neoplasia. 2004; 9 (1): 95-104.
35. Li Y, Hively WP, Varmus HE. Use of MMTV-Wnt-1 transgenic mice for studying the genetic basis of breast cancer. Oncogene. 2000; 19 (8): 1002-1009.

36. Deming SL, Nass SJ, Dickson RB, Trock BJ. C-myc amplification in breast cancer: a meta-analysis of its occurrence and prognostic relevance. $\mathrm{Br} J$ Cancer. 2000; 83 (12): 1688-1695.

37. Stewart TA, Pattengale PK, Leder P. Spontaneous mammary adenocarcinomas in transgenic mice that carry and express MTV/myc fusion genes. Cell. 1984; 38 (3): 627-637.

38. Wen J, Kawamata Y, Tojo H, Tanaka S, Tachi C. Expression of whey acidic protein (WAP) genes in tissues other than the mammary gland in normal and transgenic mice expressing $\mathrm{mWAP} / \mathrm{hGH}$ fusion gene. Mol Reprod Dev. 1995; 41 (4): 399-406.

39. Ozturk-Winder F, Renner M, Klein D, Muller $M$, Salmons B, Gunzburg WH. The murine whey acidic protein promoter directs expression to human mammary tumors after retroviral transduction. Cancer Gene Ther. 2002; 9 (5): 421-431.

40. Nielsen LL, Discafani CM, Gurnani M, Tyler RD. Histopathology of salivary and mammary gland tumors in transgenic mice expressing a human Ha-ras oncogene. Cancer Res. 1991; 51 (14): 3762-3767.

41. Green JE, Shibata MA, Yoshidome K, Liu ML, Jorcyk C, Anver MR et al. The C3(1)/SV40 T-antigen transgenic mouse model of mammary cancer: ductal epithelial cell targeting with multistage progression to carcinoma. Oncogene. 2000; 19 (8): 1020-1027.

42. Yoshidome K, Shibata MA, Couldrey C, Korach KS, Green JE. Estrogen promotes mammary tumor development in C3(1)/SV40 large T-antigen transgenic mice: paradoxical loss of estrogen receptoralpha expression during tumor progression. Cancer Res. 2000; 60 (24): 6901-6910.

43. Maroulakou IG, Anver M, Garrett L, Green JE. Prostate and mammary adenocarcinoma in transgenic mice carrying a rat C3(1) simian virus 40 large tumor antigen fusion gene. Proc Natl Acad Sci USA. 1994; 91 (23): 11236-11240.

44. Olivier M, Hollstein M, Hainaut P. TP53 mutations in human cancers: origins, consequences, and clinical use. Cold Spring Harb Perspect Biol. 2010; 2 (1): a001008.

45. Petitjean A, Achatz MI, Borresen-Dale AL, Hainaut P, Olivier M. TP53 mutations in human cancers: functional selection and impact on cancer prognosis and outcomes. Oncogene. 2007; 26 (15): 2157-2165.

46. Li B, Murphy KL, Laucirica R, Kittrell F, Medina D, Rosen JM. A transgenic mouse model for mammary carcinogenesis. Oncogene. 1998; 16 (8): 997-1007.

47. Deng CX. Tumorigenesis as a consequence of genetic instability in Brca1 mutant mice. Mutat Res. 2001; 477 (1-2): 183-189.

48. Schade B, Rao T, Dourdin N, Lesurf R, Hallett $M$, Cardiff RD et al. PTEN deficiency in a luminal ErbB2 mouse model results in dramatic acceleration of mammary tumorigenesis and metastasis. J Biol Chem. 2009; 284 (28): 19018-19026.

49. Deng CX. Conditional knockout mouse models of cancer. Cold Spring Harb Protoc. 2014; (12): 1217-1233. 